\title{
FORMAÇÃO DE PROFESSORES DA EDUCAÇÃO BÁSICA NO ENSINO SUPERIOR: DIRETRIZES CURRICULARES PÓS 1996
}

\author{
TEACHER TRAINING IN BASIC EDUCATION HIGHER EDUCATION: \\ CURRICULUM GUIDELINES AFTER 1996 \\ FORMACIÓN DE PROFESORES DE EDUCACIÓN BÁSICA EN LA \\ ENSEÑANZA SUPERIOR: DIRECTRICES CURRICULARES POS 1996
}

\author{
Leda Scheibe ${ }^{1}$ \\ Vera Lúcia Bazzo ${ }^{2}$
}

\begin{abstract}
RESUMO
O presente estudo apresenta e analisa as políticas de formação de professores para a educação básica nos cursos de graduação, licenciaturas, conforme suas principais regulações após a promulgação da Lei de Diretrizes e Bases da Educação Nacional (LDB), Lei n 9.394/1996, de 20 de dezembro de 1996 (BRASIL, 1996), atualmente em vigor. Percorre sinteticamente a trajetória histórica do país pós ditadura militar, traçando um panorama explicativo das disputas entre as diversas concepções de formação que marcaram o processo de construção dessas regulamentações. Ressalta, neste processo, a importância de uma questão central nessas definições, qual seja, o fato de, finalmente, se exigir uma formação de nível superior para formar professores. Este artigo, portanto, propõe-se, por meio de uma abordagem teórico-conceitual, analisar as regulações que foram se conformando desde a segunda metade da década de 1990 até os dias atuais, tomando como referência as diretrizes curriculares nacionais instituídas para normatizar a formação de professores para a educação básica desenvolvida nos cursos de graduação, as chamadas licenciaturas.
\end{abstract}

PALAVRAS-CHAVE: Formação de professores. Ensino superior. Diretrizes Curriculares Nacionais.

\begin{abstract}
This study presents and analyzes the teacher training policies for basic education in undergraduate courses, degrees, as its main regulations after the promulgation of the Guidelines and Bases Law of National Education (LDB), Law No. 9.394 / 1996 of December 20, 1996 (BRAZIL, 1996), currently in effect. Synthetically runs through the historical trajectory of post military dictatorship country, drawing an explanatory overview of the disputes between the different conceptions of training that marked the construction of these regulations process. Points out, in this process, the importance of a central issue in these definitions, namely, the fact that, ultimately requiring a higher level of training to train teachers. This paper therefore proposes, through a theoretical and conceptual approach to analyze the regulations that have been settling since the second half of the 1990s to the present day, with reference to national curriculum guidelines in place to regulate the training teachers for basic education developed in undergraduate courses, undergraduate calls.
\end{abstract}

KEYWORDS: Teacher training. Higher education. National Curriculum Guidelines.

\section{RESUMEN}

El presente estudio presenta y analiza las políticas de formación de profesores para la educación básica en los cursos de grado, licenciaturas, según sus principales regulaciones tras la promulgación de la Ley de Directrices y Bases de la Educación Nacional (LDB), Ley n 9.394/1996, del 20 de diciembre de 1996 (BRASIL, 1996), actualmente en vigor. Recorre sintéticamente la trayectoria histórica del país pos dictadura militar, trazando un

\footnotetext{
${ }^{1}$ Mestre em Educação pela UFRGS; doutora em Educação pela PUC-SP. Professora titular emérita da Universidade Federal de Santa Catarina. E-mail: 1scheibe@uol.com.br

${ }^{2}$ Mestre em Letras pela UFSC; doutorado em Educação pela UFRGS. Professora associada da Universidade

Federal de Santa Catarina. E-mail: vbazzo@gmail.com

Submetido em: 20/07/2016 - Aceito em: 04/09/2016.

\begin{tabular}{l|l|l|l|l|l|l} 
(C) Rev. Inter. Educ. Sup. & Campinas, SP & v.2 & n.2 & p.241-256 & maio/ago. 2016 & ISSN 2446-9424
\end{tabular}
}


panorama explicativo de las disputas entre las diversas concepciones de formación que han marcado el proceso de construcción de esas reglamentaciones. Resalta, en este proceso, la importancia de una cuestión central en esas definiciones, cual sea, el hecho de, finalmente, exigirse una formación de nivel superior para formar profesores. Este artículo, por tanto, se propone, por medio de un abordaje teórico-conceptual, analizar las regulaciones que se han ido conformando desde la segunda mitad de la década de 1990 hasta los días actuales, tomando como referencia las directrices curriculares nacionales instituidas para normalizar la formación de profesores para la educación básica desarrollada en los cursos de grado, las dichas licenciaturas.

PALABRAS CLAVE: Formación de profesores. Enseñanza superior. Directrices Curriculares Nacionales.

\section{INTRODUÇÃO}

Este artigo apresenta e analisa as políticas de formação de professores para a educação básica nos cursos de graduação, licenciaturas, conforme suas principais regulações após a Lei de Diretrizes e Bases da Educação Nacional (LDB), Lei n 9.394/1996, de 20 de dezembro de 1996 (BRASIL, 1996), atualmente em vigor.

A partir de 1985, portanto ao final da ditadura militar, o Brasil viveu um período político que se convencionou chamar de Nova República. No bojo de outras lutas pela redemocratização do país, em 1988, a nação conseguiu promulgar uma nova Constituição Federal (BRASIL, 1988), denominada de Constituição Cidadã. Como consequência deste novo ordenamento, havia que se elaborar uma nova lei de diretrizes e bases da educação. Seu processo de elaboração, porém, tomou muito tempo, uma vez que envolveu todas as forças vivas que militavam nas entidades educacionais de todas as tendências. Foi um período de grandes enfrentamentos e de muita mobilização em torno das propostas que se queria ver transformadas em lei. Depois de longamente discutida em todo o país pelas entidades organizadas dos educadores e de toda a sociedade civil, a LDB/1996 foi finalmente redigida e votada oito anos mais tarde no Congresso Nacional, numa versão minimalista, se comparada àquela consensuada pelos educadores, da lavra do então Senador Darci Ribeiro.

Tanto a Constituição de 1988 quanto a LDB de 1996 nasciam vinculadas ao fervilhante processo de redemocratização do país, que trazia entre seus anseios o direito à educação, então transformado em dever do Estado. Junto a essa forte determinação, queria-se garantir um ensino público de qualidade à população, por meio de padrões mínimos a serem atingidos. São estas duas grandes regulamentações, já com algumas alterações ou acréscimos devidos ao dinamismo da história, que até o momento presente regem e determinam as regulações que foram sendo constituídas para a orientação da formação dos docentes destinados à educação básica no país.

Desde o início de nossa história republicana, portanto desde o final do Século XIX, não se apresentaram rupturas ou fortes descontinuidades no que diz respeito às políticas de formação dos professores no país, mas houve, sim, mudanças de maior ou menor expressão na organização de seus sistemas de ensino, tanto em âmbito federal, como estadual e municipal, resultado de processos políticos mais ou menos definidores de novas

\begin{tabular}{l|l|l|l|l|l|l} 
(C) Rev. Inter. Educ. Sup. & Campinas, SP & v.2 & n.2 & p.241-256 & maio/ago. 2016 & ISSN 2446-9424 \\
\hline
\end{tabular}


institucionalidades. De qualquer forma, uma mudança importante foi o fato de se exigir uma formação de maior nível, ou seja, passou-se de uma formação em cursos de nível médio, que caracterizou fortemente toda a metade do Século XX, para uma formação de nível superior, que, ainda hoje, se apresenta como um desafio a ser vencido. (SCHEIBE e VALLE, 2007).

A formação de professores em nível superior teve seu início nas Faculdades de Filosofia, Ciências e Letras (FFCL), estruturadas em 1939, pelo Decreto Lei n. 1190. A partir desta legislação, iniciou-se como estrutura de formação o esquema "3+1", que previa para as FFCL uma seção de "Didática", destinada a habilitar os professores para lecionar no ensino secundário. Os alunos cursavam primeiro o que era denominado de "cursos ordinários" das "seções fundamentais" para que lhes fosse conferido o título de Bacharel. Ao bacharel que completasse o "curso de Didática" era concedido o diploma de Licenciado no grupo de disciplinas que formavam o seu curso de bacharelado. Percebe-se que a formação pedagógica nas licenciaturas, desde o seu início, refletiu o caráter secundário e apenas subsidiário atribuído à educação e ao ensino no âmbito da universidade, colocando-a, em geral, como mero apêndice das diferentes formas de bacharelados e desempenhando, na prática, o papel de garantir os requisitos burocráticos para o exercício do magistério (SCHEIBE, 1983).

Esta tradição, o esquema "3+ 1", iniciada na década de 1930, perdurou por muitos anos e, ainda hoje, é extremamente presente na cultura pedagógica de formação docente, embora questionada e atenuada por legislações posteriores. Segundo Saviani (2011), conteúdo e forma, aspectos constitutivos do ato docente, sempre representaram um desafio de difícil superação no sentido de sua integração nos processos de formação para a docência. Pesou para isso a consideração de que a formação de professores se esgota em estudos de cultura geral e no domínio dos conteúdos específicos da área de conhecimento correspondente à disciplina que o professor iria lecionar. Neste caso, a formação pedagógicodidática era vista como algo que deveria acontecer em decorrência do domínio dos conteúdos, e ser adquirida, portanto, na prática docente ou por meio de treinamentos específicos. Em qualquer hipótese, não caberia à universidade essa ordem de preocupações. $\mathrm{O}$ autor denomina esta prática de formação como "modelo dos conteúdos culturais-cognitivos de formação de professores” (SAVIANI, 2011, p. 9). Contrapõe-se a este encaminhamento o modelo, segundo o qual, a formação de professores deve consistir num efetivo preparo pedagógicodidático como base da formação. Além da cultura geral e da formação nos conteúdos específicos da área de conhecimento ou da disciplina para a qual dirige a sua formação docente, o curso formador deve assegurar, por meio de sua organização curricular, uma preparação pedagógico-didática concomitante. Tal prática é denominada pelo autor de "modelo pedagógico-didático de formação de professores" (SAVIANI, 2011, p. 9).

Há um reconhecimento de que a formação dos professores praticada nos cursos de ensino médio, ou seja, nas escolas normais, agora em extinção, estiveram mais próximas deste segundo modelo. Já nas instituições de ensino superior, ou seja, nos cursos de licenciatura, o modelo dos conteúdos culturais cognitivos foi sempre muito presente e predominante. 
O presente estudo, com base nessas reflexões e na literatura consequente, propõe-se, por meio de uma abordagem teórico-conceitual, analisar as regulações que foram se conformando a partir da LDB de 1996 até os dias atuais, tomando como referência as diretrizes curriculares nacionais instituídas para normatizar a formação de professores para a educação básica nos cursos de graduação, as chamadas licenciaturas.

Neste período, três resoluções elaboradas e aprovadas no âmbito do Conselho Nacional de Educação e sancionadas pelo Ministro da Educação como instrumentos orientadores dos processos de formação dos profissionais do magistério podem ser considerados os principais documentos para explicitar os processos em pauta: a primeira, a Resolução CNE/CP1, de 18 de fevereiro de 2002 (BRASIL, 2002), que instituiu Diretrizes Curriculares Nacionais para a Formação de Professores da Educação Básica, em nível superior, em curso de licenciatura, de graduação plena; a segunda, referente apenas aos cursos de pedagogia, foi aprovada pela Resolução n. 1, de 15 de maio de 2006 (BRASIL, 2006b), Diretrizes Curriculares Nacionais para o Curso de Graduação em Pedagogia; e a terceira, a Resolução CNE/CP n. 02/2015, de $1^{\circ}$ de julho de 2015 (BRASIL, 2015), que instituiu as Diretrizes Curriculares Nacionais para a formação inicial e continuada em nível superior de profissionais do magistério para a Educação Básica (cursos de licenciatura, cursos de formação pedagógica para graduados e cursos de segunda licenciatura), que definiu, conforme seu artigo primeiro: "princípios, fundamentos, dinâmica formativa e procedimentos a serem observados nas políticas, na gestão e nos programas e cursos de formação, bem como no planejamento, nos processos de avaliação e de regulação das instituições de educação que as ofertam". Esta última, invalidou e substituiu a Resolução CNE/CP1, de 2002. São estes os documentos em análise neste estudo.

As discussões que ocorreram no processo de definição destas normas evidenciaram os conflitos subjacentes à área educacional e oportunizaram a percepção da complexidade das relações que se estabelecem entre a ação pública e as demandas sociais. Efetivamente, a política pública não acontece como iniciativa isolada e em um sentido único, mas sim numa forte interação entre demanda social e ação governamental, tão bem explicitada por Souza (2016).

Iniciaremos com uma breve análise do conceito de educação básica que se encontra subjacente à formação em discussão, para depois entrar nos itens específicos relacionados com as diretrizes curriculares nacionais para a formação de professores na educação superior.

\section{A EDUCAÇÃO NO BRASIL}

A LDB de 1996, no artigo 21, definiu a existência de dois grandes níveis na educação brasileira: a Educação Básica (EB) e a Educação Superior (ES). Genericamente, a expressão educação básica pode significar o conjunto de atividades educativas iniciais, formais ou não formais, que se destinam às necessidades básicas de aprendizagem. Tal denominação, no 
entanto, tendo como referência a nossa legislação, passou a designar o nível de educação que articula a educação infantil, o ensino fundamental e o ensino médio. A educação infantil, primeira etapa da EB, contempla dois momentos distintos: creches ou entidades equivalentes para o atendimento de crianças de zero a três anos; e pré-escola, destinada às crianças de quatro a seis anos. Já o ensino fundamental contempla recentemente nove anos de escolarização, conforme legislação aprovada em 2009, que alterou o anteriormente disposto na LDB. O ensino médio, etapa final da $\mathrm{EB}$, tem como duração mínima três anos de escolarização. (SCHEIBE, 2014).

Segundo Cury (2002), a articulação destas três etapas de ensino num mesmo nível educacional pode ser considerada como uma formulação avançada, que deve representar a busca por um desenvolvimento sequencial e orgânico na sua organização. Destacamos aqui, com apoio nos dados do Censo da Educação Básica de 2015 (MEC/INEP 2015), a existência de cerca de cinquenta milhões de alunos neste nível de ensino, dos quais não menos do que quarenta milhões nas redes públicas, evidenciando a significativa importância dessas redes para o atingimento das metas educacionais conforme preconizadas na Constituição Federal Direito de todos e dever do Estado.

A universalização da educação básica para toda a população, ou seja, sua extensão a todo cidadão brasileiro como um direito social e dever do Estado, no entanto, ainda é uma grande meta a ser atingida. Até 2009, o marco legal delimitava a obrigatoriedade escolar ao ensino fundamental, a partir dos seis anos de idade. A Emenda Constitucional no 59, de 11 de novembro de 2009 (BRASIL, 2009a), porém, expandiu a obrigatoriedade de frequência à escola aos indivíduos de 4 a 17 anos, a ser implementada de forma progressiva até 2016. Tal expansão teve um significado particularmente importante para a ampliação da oferta de ensino público e gratuito na educação infantil (pré-escola), assim como no ensino médio a uma maior quantidade de crianças e de jovens, até então a descoberto de tal obrigatoriedade.

A docência na educação básica representa, portanto, uma mediação fundamental, extremamente visada, nas diferentes perspectivas que determinam os projetos adotados para 0 desenvolvimento do país. Por um lado, perseguem-se parâmetros dominados por uma visão economicista e mercadológica da educação; por outro, a busca de uma educação com qualidade social alicerçada num projeto de emancipação e inserção de todos no projeto de uma nação efetivamente democrática.

\section{A LDB/1996 E A FORMAÇÃO DE PROFESSORES PARA A EDUCAÇÃO BÁSICA}

A transição para a chamada Nova República, como já mencionado, começa a se fazer sentir no país a partir dos anos de 1970, quando movimentos e manifestações eclodem em todo o país, visando à derrubada do regime militar. No centro das transformações requeridas, em busca de uma sociedade participativa e cidadã, a definição de uma política de formação de professores adquire especial importância. $\mathrm{O}$ arcabouço jurídico para as transformações institucionais e educacionais reivindicadas foi construído coletivamente no processo que resultou na Constituição Federal, promulgada em 1988. Seguiu-se a ela, por necessária, uma

\begin{tabular}{l|l|l|l|l|l|l} 
(C) Rev. Inter. Educ. Sup. & Campinas, SP & v.2 & n.2 & p.241-256 & maio/ago. 2016 & ISSN 2446-9424
\end{tabular} 
nova LDB. Foram mais oito anos de intensos trabalhos, num longo processo de disputa e de algumas vitórias para o movimento dos educadores, que a discutiram e elaboraram num inédito processo de discussão coletiva somente possível pelas condições favorecidas pelo então processo de redemocratização do país.

Esta lei privilegiou um modelo de formação docente vinculado ao nível superior, embora não necessariamente articulado aos critérios exigidos para uma formação universitária, qual sejam, o desenvolvimento da pesquisa e da extensão na produção de novos conhecimentos, mas deu ênfase maior a uma preparação técnico-profissionalizante de ensino superior (SCHEIBE, 2004), evidenciada em regulamentações com base em novos formatos institucionais tais como os institutos superiores de educação e seus propostos cursos normais superiores. Estas novas instâncias educativas foram planejadas para abrigar cursos superiores com redução em seus tempos de duração e com vistas a atender a um maior número de estudantes, o que demandava um certo aligeiramento da formação com consequente simplificação do trabalho pedagógico. Ao mesmo tempo, continuou em vigor, por tempo indeterminado, a norma que consta do artigo 62 da LDB, no Título VI, permitindo, como formação mínima e destinada ao exercício do magistério na educação infantil e nos anos iniciais do ensino fundamental, a formação de nível médio na modalidade normal. Tal determinação foi mais recentemente ratificada pela Lei n. 12796, de 04 de abril de 2013 (BRASIL, 2013), que, ao fazer algumas alterações na LDB, manteve a possibilidade dessa formação como exigência mínima para o exercício do magistério nos níveis iniciais de escolarização, numa reafirmação inaceitável de que para ser professor das fases iniciais da educação basta uma formação de nível meramente técnico, conseguido em cursos de nível médio.

Os propostos Institutos Superiores de Educação foram incorporados à lei numa tentativa de substituição do papel previsto para as Faculdades de Educação existentes nas instituições universitárias. Deveriam, no entanto, ir além desses espaços - Centros de Educação, Faculdades de Educação, Departamentos/Setores de Educação - que, ao longo do tempo, foram se construindo no interior das universidades, e nos quais as licenciaturas cursos para a formação de professores - ficavam sob a responsabilidade tanto de departamentos vinculados aos conteúdos educacionais e pedagógicos quanto de departamentos responsáveis pelo ensino das disciplinas de conteúdo específico. Os Institutos poderiam ser, então, instituições não necessariamente universitárias, mas menos exigentes nos critérios da relação indissociável entre ensino, pesquisa e extensão, que caracterizam as universidades, transformando-se em local exclusivo para a formação dos profissionais da educação. Já na tentativa de regulamentação destes institutos, instaurou-se grande polêmica, liderada pelas entidades educacionais e que logrou mudanças importantes, principalmente no tocante à "exclusividade" que se queria para esses espaços na formação de professores. Ao mesmo tempo, ressurgia uma forte reivindicação no sentido de que o lócus dessa formação continuasse a ser as instituições universitárias. 
Outra questão bastante polêmica e que continuava a figurar na recém aprovada LDB/1996 referia-se aos cursos de Pedagogia. Para esses, a lei consagrava o papel de formadores de profissionais de educação para funções de administração, planejamento, inspeção, supervisão e orientação educacional destinada à educação básica. Aos cursos normais superiores deveria caber a tarefa de formar os professores para a educação infantil e para os anos iniciais do ensino fundamental.

Por força do movimento organizado dos educadores, que saiu em campo para questionar tais ordenamentos, o Curso de Pedagogia manteve-se seguindo sua missão autoelegida, isto é, formando os professores para a educação infantil e para os anos iniciais do ensino fundamental, segundo o entendimento até então defendido pelas entidades representativas da área da educação e seguido pela grande maioria das universidades públicas do país. Tal atitude de resistência, quase uma desobediência civil, acabou levando os cursos normais superiores, criados ao sabor da novel aprovada legislação, à extinção gradativa. Com a aprovação da Resolução que definiu em 2006 as diretrizes curriculares nacionais para o Curso de Pedagogia, e que estabeleceu como base de formação para este curso a docência na educação infantil e anos iniciais do ensino fundamental, os cursos normais superiores foram oficialmente extintos, por ausência de finalidade.

Após a promulgação da LDB, foram produzidas regulações em novas legislações, muitas delas relacionadas à organização e ao currículo dos cursos de formação de professores para a educação básica. Bazzo (2006) destaca entre as ênfases predominantes: estruturação dos currículos por competências; instituição de parâmetros curriculares nacionais em todos os níveis de escolarização; introdução de processos de avaliação do desempenho dos professores e tentativa de relacionar diretamente tais índices ao desempenho dos alunos; instituição de políticas de promoção por mérito e gratificações por produtividade; ênfases em noções como eficiência e eficácia, entre outros conceitos do mundo empresarial e do mercado.

Nesse contexto, foram construídas as DCNs para a formação dos professores da educação básica, que passamos a apresentar a seguir.

\section{AS DCNS PARA A FORMAÇÃO DE PROFESSORES DA EDUCAÇÃO BÁSICA APROVADAS PELA RESOLUÇÃO CNE/CP 1/2002}

As diretrizes aprovadas pela Resolução CNE/CP n.01, de 18 de fevereiro de 2002, (BRASIL, 2002) apresentaram um conjunto de princípios, fundamentos e procedimentos a serem observados na organização institucional e curricular das instituições formadoras, como uma base comum nacional de formação docente. Dos pressupostos e orientações emanadas do Parecer que antecedeu esta Resolução - Parecer CNE/CP n. 09/2001, de 08 de maio de 2001 (BRASIL, 2001) -, surgiram exigências de reconstrução na organização e no desenvolvimento dos cursos de licenciatura, assim como de mudança de mentalidade dos formadores que neles atuavam e das instituições que lhes davam abrigo. Segundo Bordas (2009), as instituições formadoras de todo o país passaram a discutir e mesmo a implantar reformas nas estruturas curriculares dos cursos de licenciatura, no sentido de atender às normas legais, que rompiam com uma tradição iniciada no país em 1934, quando da criação

\begin{tabular}{l|l|l|l|l|l|l} 
(C) Rev. Inter. Educ. Sup. & Campinas, SP & v.2 & n.2 & p.241-256 & maio/ago. 2016 & ISSN 2446-9424 \\
\hline
\end{tabular} 
dos primeiros cursos superiores de formação de professores, cuja estrutura é conhecida como modelo denominado de " $3+1$ " (três anos de conteúdos específicos da respectiva área do conhecimento e um das chamadas disciplinas pedagógicas). Por mais de sessenta anos foi este o modelo que ordenou tais cursos, tendo, ainda hoje, uma aceitação explícita de grande parte dos docentes que neles atuam, particularmente daqueles vinculados às disciplinas de conteúdos específicos de cada área de dada licenciatura. Os docentes que atuam nas áreas de formação pedagógica, aqueles que, em um ano, deveriam transformar os estudantes em profissionais do magistério, foram os principais responsáveis pela condução das discussões a respeito da substituição de tal modelo.

É importante dizer que esta legislação, emanada do Conselho Nacional de Educação (CNE), representou um avanço importante ao estabelecer uma configuração específica aos cursos de licenciatura, distinguindo-os dos cursos de bacharelado. Bordas (2009) ressaltou que essa nova perspectiva conceitual e também política das diretrizes de 2002 respondeu às demandas dos educadores preocupados com a melhoria da formação, embora tenham também surgido contestações e questionamentos a respeito de vários aspectos da nova legislação, tais como: orientação epistemológica predominante nos documentos dando ênfase sobre a formação "na prática", ou, ainda, no conceito de "competências"; seu espírito pragmatista e tendência de aligeiramento da formação docente, ao estipular o mínimo de 2800 horas /aula para os cursos, sem estabelecer o tempo mínimo para concretizar o seu período de estudos. (FREITAS, 2002).

Questões mais pontuais também foram alvo de grande discussão, como o desejo de que a carga horária mínima exigida para o curso fosse mais extensa, além de restarem dúvidas a respeito da configuração dos estágios curriculares e mesmo sobre o entendimento do conceito de práticas como Componentes Curriculares - PCCs, entre outras.

As maiores resistências à implantação das diretrizes, todavia, aconteceram nas áreas específicas em relação à necessidade de dedicarem a devida atenção e o tempo requerido às práticas pedagógicas então denominadas de Componentes Curriculares - PCCs, desenvolvidas seja sob responsabilidade dessas mesmas disciplinas específicas ou compartilhadas com as disciplinas da área pedagógica. Por outro lado, o significativo aumento de horas destinadas a atividades vinculadas à prática docente constante nesta legislação, indicativas do que tem sido denominado de epistemologia da prática, foi uma das questões que mais tomaram a atenção dos movimentos de educadores. Preocupados em defender a necessidade de uma formação teórica consistente na área da educação, se se pretende formar professores capazes de dar conta de sua complexa atividade profissional, temiam por um aligeiramento desses conteúdos e saberes.

A implantação destas regulações trouxe à tona, mais uma vez, a persistente divisão entre teoria e prática, motivo de muitos escritos dos teóricos da área. Neste sentido, Saviani (2007) salienta a necessidade de superação dessa dicotomia que, ao longo da história da educação, tem se mantido quer dando prioridade à teoria sobre a prática, subordinando a prática à teoria; quer subordinando a teoria à prática, dissolvendo, em última análise, a teoria na prática. $\mathrm{O}$ autor reivindica uma "unidade compreensiva" entre estes dois polos, superando sua compreensão como mutuamente excludentes. Tal superação, no entanto, continua sendo 
um grande desafio para os cursos de formação docente. É ainda muito presente a concepção "divisionista" que perpassa todo o processo de formação, incidindo sobre o modo como são selecionados, organizados e ensinados os próprios conteúdos específicos de cada área, como deixa claro o Parecer CNE/CP n. 09/2001, de 08 de maio de 2001, já citado.

Também a dimensão interdisciplinar nos currículos de formação foi salientada no referido parecer. Anuncia-se tal perspectiva como fundamental para se pensar a organização de um percurso de formação para professores, uma vez que o desenvolvimento da ciência caminha na direção da intercomplementaridade dos conhecimentos.

Finalmente, a Resolução $n^{0}$ 1/2002 e o Parecer que a fundamenta assumiram como princípio a flexibilidade curricular, ao permitir um certo grau de autonomia em relação aos componentes curriculares de cada curso sem abandonar a exigência de um núcleo básico comum às licenciaturas, o que envolve a formulação de princípios orientadores da formação expressos nos projetos pedagógicos dos cursos, uma listagem das competências a serem alcançadas pelos futuros docentes, assim como a seleção dos conteúdos disciplinares essenciais ao desenvolvimento dessas competências.

Estas Diretrizes Curriculares Nacionais (DCN), é importante salientar, constituíram-se como uma nova formulação curricular para todos os cursos de licenciatura e modalidades de ensino no país após a LDB de 1996. Vieram para substituir os currículos mínimos que vigoraram até então e que estabeleciam a unidade nacional curricular de forma mais rígida (disciplinas obrigatórias, por exemplo, para todo o país). As DCN, ao apresentarem uma estrutura mais flexível, possibilitaram maior diversidade disciplinar nos currículos dos cursos.

\section{DIRETRIZES CURRICULARES NACIONAIS PARA O CURSO DE GRADUAÇÃO EM PEDAGOGIA}

Aprovadas pela Resolução n. 1, de 15 de maio de 2006 (BRASIL, 2006b), as Diretrizes Curriculares Nacionais para o Curso de Graduação em Pedagogia passaram por um longo processo de tensionamento entre propostas antagônicas até sua aprovação. O seu processo de construção envolveu comissões internas do Ministério da Educação, Comissões Bicamerais do Conselho Nacional de Educação, Comissões de Especialistas de Ensino de Pedagogia, entidades científicas e associações da área da educação, tais como a Associação Nacional pela Formação dos Profissionais da Educação (Anfope), Associação Nacional de Pós-Graduação e Pesquisa em Educação (Anped), Fórum Nacional de Diretores de Faculdades, Institutos, Centros de Educação ou Equivalentes das Universidades Públicas Brasileiras (Forumdir), Centro de Estudos Educação e Sociedade (Cedes), e Associação Nacional de Política e Administração da Educação (Anpae), no período de 1997 a 2006 (DURLI e BAZZO, 2008).

Entre as principais mudanças estabelecidas para o Curso de Pedagogia pelas diretrizes curriculares destacam-se a alteração de sua finalidade, a extinção das habilitações, o aumento da carga horária mínima para a integralização do curso e a flexibilização curricular. 
Atualmente, tendo em vista estas diretrizes, o Curso de Pedagogia se destina à:

[...] formação de professores para exercer funções de magistério na Educação Infantil e nos anos iniciais do Ensino Fundamental, nos cursos de Ensino Médio, na modalidade Normal, de Educação Profissional na área de serviços e apoio escolar e em outras áreas nas quais sejam previstos conhecimentos pedagógicos.

Parágrafo único: As atividades docentes também compreendem participação na organização e gestão de sistemas e instituições de ensino, englobando:

I - planejamento, execução, coordenação, acompanhamento e avaliação de tarefas próprias do setor da Educação;

II - planejamento, execução, coordenação, acompanhamento e avaliação de projetos e experiências educativas não-escolares;

III - produção e difusão do conhecimento científico-tecnológico do campo educacional, em contextos escolares e não-escolares. (BRASIL, 2006b).

$\mathrm{Na}$ organização curricular anterior, datada de 1969, era privilegiada a existência de habilitações, sendo que apenas aquelas destinadas à formação de docentes caracterizavam-se como licenciaturas. As dedicadas à formação de profissionais denominados especialistas em assuntos educacionais eram formalizadas como bacharelados. A atual resolução extinguiu as habilitações, e o curso passou a ser uma licenciatura, com base docente obrigatória, contrapondo-se à concepção de pedagogo desvinculada de uma preparação para a docência.

Por exigência da LDB de 1996, no entanto, as diretrizes admitiram a formação dos especialistas, desde que mantida a base docente na sua formação, atendendo assim ao Art.64 da LDB. A duração do curso foi estabelecida em 3.200 horas de efetivo trabalho acadêmico, reivindicação das associações científicas de defesa da formação do educador. Note-se que esta determinação de carga horária mínima para o Curso de Pedagogia ultrapassou aquela regulamentada pelas DCN de 2002, que definiam 2.800 horas como carga horária mínima para os cursos de licenciatura.

As diretrizes para o Curso de Pedagogia propõem uma organização ampla e sugerem que os cursos contemplem três núcleos de estudos, a saber: 1) núcleo de estudos básicos; 2) núcleo de aprofundamento e diversificação de estudos e 3) núcleo de estudos integradores, para os quais foram estabelecidos tempos curriculares diferenciados. A identidade construída pela discussão nacional elegeu os aspectos teóricos dos conteúdos como aqueles aos quais deve se destinar a maior carga horária do curso - 2800 horas, de um conjunto de 3200 . Sugere-se também, no corpo das diretrizes, que a articulação destes núcleos e dos conhecimentos que lhes dão sustentação seja orientada pelos princípios de interdisciplinaridade, contextualização, democratização, pertinência e relevância social, ética e sensibilidade afetiva e estética.

Grande parte dos cursos de pedagogia, mesmo antes da homologação dessas diretrizes, já vinha se orientando nos moldes assumidos por esta regulação. O Conselho Nacional de Educação, a quem compete o estabelecimento da normatização curricular dos cursos, instituiu, de certa forma, os elementos constitutivos da identidade do curso que já vinha se implantando entre aqueles que acompanhavam a discussão nacional, a qual defendia 
a formação dos professores da Educação Infantil e dos anos iniciais do Ensino Fundamental como a base comum docente para o Curso de Pedagogia.

Outro elemento importante na definição dessa identidade de curso aparece nos Artigos $2^{\circ}$ e $7^{\circ}$ das referidas diretrizes, os quais anunciam a centralidade da docência entre as diversas finalidades formativas do curso.

Art. $2^{\circ}$ As Diretrizes Curriculares para o Curso de Pedagogia aplicam-se à formação inicial para o exercício da docência na Educação Infantil e nos anos iniciais do Ensino Fundamental, nos cursos de Ensino Médio, na modalidade Normal, e em cursos de Educação Profissional na área de serviços e apoio escolar, bem como em outras áreas nas quais sejam previstos conhecimentos pedagógicos. (Grifo nosso), ( BRASIL, 2006b).

Também o Art. $7^{\circ}$, inciso II da Resolução em pauta, especifica que os estágios supervisionados devem, prioritariamente, realizar-se na Educação Infantil e nos anos iniciais do Ensino Fundamental. Da mesma forma, as referências feitas em relação à gestão e à pesquisa indicam que estes conteúdos e as funções que propiciam - de gestor e de pesquisador educacionais, devam ser acrescidas à docência.

Tais diretrizes, mesmo sendo concebidas sob a égide das orientações das DCNs de 2002, anteriormente tratadas, deram ao curso de Pedagogia o desenho que vinha sendo requerido pelo movimento das entidades educacionais, não com pleno consenso, mas pela maioria dos seus componentes. Ou seja: o estabelecimento deste curso como o lócus de formação dos docentes da Educação Infantil e dos anos iniciais do Ensino Fundamental, avançando em relação à LDB, que estabelecia para este curso a formação de especialistas em educação, numa concepção considerada desarticuladora da base docente como princípio de formação de todos os educadores. Ao mesmo tempo, é possível considerar que estas diretrizes avançaram em algumas das proposições que vieram a caracterizar as novas diretrizes que apresentaremos a seguir.

Diretrizes Curriculares Nacionais para a formação inicial e continuada em nível superior de profissionais do magistério para a Educação Básica (cursos de licenciatura, cursos de formação pedagógica para graduados e cursos de segunda licenciatura) e para a formação continuada, de 2015

A Resolução CNE/CP n. 02, de 2015 (BRASIL, 2015), que define as Diretrizes Curriculares Nacionais para a Formação Inicial em Nível Superior (cursos de licenciatura, cursos de formação pedagógica para graduados e cursos de segunda licenciatura) e para a Formação Continuada, está atualmente em implantação e dá continuidade, em vários aspectos, às disposições das diretrizes anteriores, sem, no entanto, deixar de apresentar uma concepção geral diferenciada, qual seja, compreender a formação e o desenvolvimento profissional numa perspectiva superadora daquela que colocava como seu centro articulador o desenvolvimento de competências. A nova legislação incorpora de forma mais aprofundada as ideias produzidas nos anos 1980 e 1990, no interior de um amplo movimento orquestrado pelas entidades já citadas anteriormente. 
Estas DCNs, recentemente formuladas, incorporaram inúmeras mudanças ocorridas no âmbito da educação, no período pós 2002, e que dizem respeito à formação e à valorização dos profissionais da educação. Assim, reafirmam regulamentações tais como: a alteração no Artigo 61 da LDB pela Lei 12.014, de 2009 (BRASIL, 2009c), que discriminou as categorias de trabalhadores que devem ser considerados "profissionais da educação", explicitando a necessidade de sua formação em cursos reconhecidos; a obrigatoriedade do Estado (nas suas três esferas, União, Distrito Federal, Estados e Municípios) de promover, em regime de colaboração, a formação inicial e a continuada dos professores, a capacitação dos profissionais do magistério, realizadas de preferência no ensino presencial, regulamentada pela Lei 12.056, de 2009 (BRASIL, 2009b); a exigência de compromisso dos entes federativos de propiciar o acesso e a permanência dos profissionais em cursos de formação de docentes em nível superior para atuar na educação básica pública, estabelecido pela Lei $n^{\circ}$ 12.796 (BRASIL, 2013). Esta lei cita especificamente a necessidade de manutenção do Programa Institucional de Bolsa de Iniciação à Docência (Pibid), oferecido a estudantes matriculados em cursos de licenciatura, de graduação plena, nas instituições de educação superior.

As atuais diretrizes também incorporam outros aparatos legais como a Lei n. 11.494, de 2007 (BRASIL, 2007a), que regulamenta o Fundeb; a Lei n. 11.502, de 2007 (BRASIL, 2007b), que modificou as competências e a estrutura organizacional da Fundação Coordenação de Aperfeiçoamento de Pessoal de Nível Superior - CAPES, a qual passou a ser também responsável por induzir e fomentar a formação inicial e continuada dos profissionais do magistério da educação básica no país; a Lei n. 11.738, de 2008 (BRASIL, 2008), que regulamenta o piso salarial profissional nacional para os profissionais do magistério público da educação básica; o Decreto n. 6.755, de 2009 (BRASIL 2009d), que instituiu a Política Nacional de Formação de Profissionais do Magistério da Educação Básica e disciplinou a atuação da Capes no fomento a programas de formação inicial e continuada; a Lei n. 13.005, de 25 de junho de 2014 (BRASIL, 2014), que aprovou o Plano Nacional de Educação - PNE, especialmente as metas (15 a 18) e suas estratégias direcionadas aos profissionais do magistério da Educação Básica. E, mais recentemente, o Decreto n. 8.752, de 9 de maio de 2016, que regulamenta a Política Nacional de Formação dos Profissionais da Educação Básica (BRASIL, 2016), atendendo ao que dispôs o PNE/2014.

Entre os princípios norteadores para a formação inicial e continuada dos profissionais da educação, as DCN de 2015 apresentam a necessidade de uma sólida formação teórica e interdisciplinar; a unidade entre teoria e prática na formação; trabalho coletivo e compromisso social; gestão democrática; necessidade de avaliação e regulação dos cursos de formação.

Nessas diretrizes são previstas três grandes modalidades de cursos de formação em nível superior, quais sejam: cursos de graduação de licenciatura; cursos de formação pedagógica para graduados não licenciados; e cursos de segunda licenciatura. Tais cursos poderão ser organizados em áreas especializadas, por componente curricular, ou mesmo por campo de conhecimento e/ou interdisciplinar. Para os cursos de licenciatura foi estabelecido o mínimo de carga horária de 3.200 (três mil e duzentas) horas de efetivo trabalho acadêmico, em cursos com duração de, no mínimo, 8 (oito) semestres ou 4 (quatro) anos, sendo que desta carga horária 400 (quatrocentas) horas deverão ser de prática como componente curricular, distribuídas ao longo do processo formativo; e 400 (quatrocentas) horas deverão ser de 
estágio supervisionado, na área de formação e atuação na educação básica, contemplando também outras áreas específicas, dependendo do projeto de curso da instituição.

A articulação entre formação inicial e continuada com condições de trabalho, salário e planos de carreira atrativos é o tripé enfatizado pelas diretrizes, com base nas reivindicações da área educacional e dos movimentos em defesa da formação e da valorização do professor.

\section{CONCLUSÕES}

As novas diretrizes aprovadas em 2015 e suas regulamentações oferecem uma base comum nacional para a formação dos profissionais da educação definida pela legislação brasileira. Preveem também incorporações diversificadas, a serem incluídas regional ou localmente. Trazem uma concepção de educação como processo emancipatório e permanente e o reconhecimento da especificidade do trabalho docente enquanto expressão da articulação entre teoria e prática.

Dourado (2015), um dos principais articuladores da sistematização destas diretrizes, considera que elas se constituem num passo importante para possibilitar ao egresso o conhecimento da instituição educativa na qual deverá exercer sua profissão. Para tanto, os cursos de formação devem propiciar-lhe habilidades de pesquisa e de atuação profissional no ensino, em sua gestão e organização, e na gestão de instituições de educação básica. A regulação em pauta, segundo o autor, não se furta de apresentar os conceitos de educação, de docência, de currículo, de formação inicial e continuada, implícitos nas orientações, e que pretendem assegurar nos processos de formação estudos teórico-práticos, investigação e reflexão crítica.

Tal como já estava posto nas DCN de 2002, as atuais diretrizes também enfatizam a necessidade de as instituições formadoras elaborarem seu projeto institucional de formação, o que implica numa articulação com os sistemas e redes de ensino e com as instituições de educação básica, além das demais instâncias envolvidas no trabalho educativo e, particularmente, com o planejamento estratégico pretendido hoje pelos Fóruns Estaduais Permanentes de Apoio à Formação Docente.

Ser profissional implica dominar um profundo conteúdo de conhecimento que caracteriza o trabalho a ser realizado, associado a um certo grau de autonomia na atividade a ser desenvolvida. Esta busca está implícita nas diretrizes que envolvem, articuladamente, aspectos e políticas que dizem respeito à formação inicial e continuada, carreira, salários e condições de trabalho. Segundo Fanfani (2008), existe algo de vocacional no trabalho do professor, o que é importante em qualquer área de trabalho. No entanto, esta dimensão vocacional, historicamente hiperdimensionada entre os profissionais da educação, precisa ser equilibrada com o profissionalismo que permite aos nossos trabalhadores da educação 
enfrentar, cada vez com maior qualificação, a exclusão social contribuindo para o alcance da necessária inclusão escolar. Este é o grande desafio do nosso tempo.

\section{REFERÊNCIAS}

ANFOPE. Documento Final do Encontro Nacional do Forumdir e Encontro Regional da Anfope Sul. Florianópolis, 6 e 7 de junho de 2016.

BAZZO, V. L. As consequências do processo de reestruturação do Estado brasileiro sobre a formação dos professores da educação básica: algumas reflexões. In: PERONI, V. M.V. [S.n.t.].

BAZZO, V.L.; PEGORARO, L (Org.). Dilemas da educação brasileira em tempos de globalização neoliberal: Entre o público e o privado. Porto Alegre: Editora da UFRGS, 2006, p.25-48.

BORDAS, M. Relatório final de pesquisa do projeto. Subsidio a formulação e avaliação de políticas educacionais brasileiras: avaliação da implantação das Diretrizes Curriculares Nacionais para a formação de professores nos cursos de licenciatura. Porto Alegre:

CNE/UNESCO, 2009.

BRASIL, Decreto n. 8.752 de 9 de maio de 2016. Dispõe sobre a Política Nacional de Formação dos Profissionais da Educação Básica. Ministério da Educação. Brasília, 2015. Brasília, 2016.

BRASIL. Resolução CNE/CP n. 02/2015 de 1 de julho de 2015. Define as Diretrizes Curriculares Nacionais para a formação inicial em nível superior (cursos de licenciatura, cursos de formação pedagógica para graduados e cursos de segunda licenciatura) e para a formação continuada. Ministério da Educação. Brasília, 2015.

BRASIL. Lei n. 13.005, de 25 de junho de 2014. Aprova o Plano Nacional de Educação PNE e dá outras providências. Brasília, 2014.

BRASIL. Lei n. 12796, de 04 de abril de 2013. Altera a Lei no 9.394, de 20 de dezembro de 1996, que estabelece as diretrizes e bases da educação nacional, para dispor sobre a formação dos profissionais da educação e dá outras providências. Brasília, 2013.

BRASIL. Emenda Constitucional n ${ }^{\circ}$ 59, de 11 de novembro de 2009 (2009). Acrescenta $\$ 3^{\mathbf{o}}$ ao art. 76. Brasília, 2009a.

BRASIL. Lei 12.056, de 13 de outubro de 2009. Altera o art. 62 da Lei no 9.394, de 20 de dezembro de 1996. Brasília, $2009 b$.

BRASIL. Lei n. 12.014, de 06 de agosto de 2009. Altera o art. 61 da Lei no 9.394, de 20 de dezembro de 1996, com a finalidade de discriminar as categorias de trabalhadores que se devem considerar profissionais da educação. Brasília, 2009c.

BRASIL. Decreto n. 6.755, de 29 de janeiro de 2009. Institui a Política Nacional de

\begin{tabular}{l|l|l|l|l|l|l} 
(C) Rev. Inter. Educ. Sup. & Campinas, SP & v.2 & n.2 & p.241-256 & maio/ago. 2016 & ISSN 2446-9424
\end{tabular}


Formação de Profissionais do Magistério da Educação Básica, disciplina a atuação da Coordenação de Aperfeiçoamento de Pessoal de Nível Superior - CAPES no fomento a programas de formação inicial e continuada, e dá outras providências. Brasília, 2009d.

BRASIL. Lei n. 11.738, de 16 de julho de 2008. Regulamenta a alínea "e" do inciso III do caput do art. 60 do Ato das Disposições Constitucionais Transitórias, para instituir o piso salarial profissional nacional para os profissionais do magistério público da educação básica. Brasília, 2008.

BRASIL. Lei n. 11.494, de 2007 de 10 de junho de 2007. Regulamenta o Fundo de Manutenção e Desenvolvimento da Educação Básica e de Valorização dos Profissionais da Educação - FUNDEB. Brasília, 2007a.

BRASIL. Lei n. 11.502 de 2007 de 11 de julho de 2007. Modifica as competências e a estrutura organizacional da fundação Coordenação de Aperfeiçoamento de Pessoal de Nível Superior - CAPES. Brasília, 2007.

BRASIL. Emenda Constitucional n. 53, de 19 de dezembro de 2006. Dá nova redação aos arts. $7^{\circ}, 23,30,206,208,211$ e 212 da Constituição Federal e ao art. 60 do Ato das Disposições Constitucionais Transitórias. Brasília. 2006a.

BRASIL. Resolução CNE/CP n. 1, de 15 de maio de 2006. Institui Diretrizes Curriculares Nacionais para o Curso de Graduação em Pedagogia, licenciatura. Ministério da Educação. Brasília, 2006b.

BRASIL. Resolução CNE/CP n.01 de 18 de fevereiro de 2002. Institui Diretrizes Curriculares Nacionais para a Formação de Professores da Educação Básica, em nível superior, curso de licenciatura, de graduação plena. Ministério da Educação. Brasília, 2002 .

BRASIL. Parecer CNE/CP n. 09/2001, de 08 de maio de 2001. Diretrizes Curriculares Nacionais para a Formação de Professores da Educação Básica em nível superior. Ministério da Educação. Brasília, 2001.

BRASIL. Lei n. 9.394/1996, de 20 de dezembro de 1996. Lei de Diretrizes e Bases da Educação Nacional. Ministério da Educação. Brasília, 1996.

BRASIL. Constituição da República Federativa do Brasil de 1988. Brasília: Senado Federal, 1988.

BRZEZINSKI, I. (Org.). Anfope em movimento: 2008-2010. Brasília: Liber Livro, Anfope \& Capes, 2011.

CURY, C. R. J. Direito a Educação: Direito à igualdade, direito à diferença. Cadernos de Pesquisa, São Paulo, n.116, p. 245-262, jul. 2002.

DOURADO, L. F. Diretrizes Curriculares Nacionais para a Formação Inicial e Continuada dos Profissionais do Magistério da Educação Básica: concepções e desafios. Educação e Sociedade, São Paulo, v. 36, n. 131, p.299-324, abr./jun. 2015. 
DURLI, Z.; BAZZO, V. L. Diretrizes Curriculares para o curso de pedagogia: Concepções em disputa. Atos de Pesquisa em Educação, Blumenau, v.3, n. 2, p. 201-226, maio/ago. 2008.

FANFANI, E. T. Sociología de la profesionalización docente. In: PROFESIONALIZAR a los profesores sin formación inicial: puntos de referencia para actuar Seminario Internacional. Buenos Aires, 2 a 6 de junho de 2008.

FREITAS, H. C. L. Formação de professores no Brasil: 10 anos de embate entre projetos de formação. Educação e Sociedade. Campinas, v.23, n.80, p. 137-168, set. 2002.

MEC/INEP. Censo Escolar da Educação Básica 2014: resumo técnico. Brasília: INEP, 2015.

SAVIANI, D. Formação de professores no Brasil: dilemas e perspectivas. Poiésis Pedagógica. Catalão, v.9, n.1, p.7-19, jan./jun. 2011.

SAVIANI, D. Pedagogia: o espaço da educação na universidade. Cadernos de Pesquisa, São Paulo, v. 37, n. 130, p. 99-134, jan./abr. 2007.

SCHEIBE L. O projeto de profissionalização docente no contexto da reforma educacional iniciada nos anos 1990. Educar em Revista, Curitiba, n.24, p.177-193, 2004.

SCHEIBE, L. A formação pedagógica do professor licenciado: contexto histórico. Perspectiva. Florianópolis, v.1, n.1, p.31-45, 1983.

SCHEIBE. L; VALLE, I. R. A formação dos professores no Brasil e em Santa Catarina: do normalista ao diplomado na educação superior. In: NASCIMENTO, A. D.; HETKOWSKI, T. M. (Org.). Memória e formação de professores. Salvador: EDUFBA, 2007. p.257-272.

SCHEIBE. L. Educação Básica no Brasil: Expansão e qualidade. Retratos da Escola, Brasília, v.8, n.14, p.101-114, jan./jul. 2014.

SOUZA, A. R. A política educacional e seus objetos de estudo. Revista de Estudios Teóricos y Epistemológicos en Política Educativa, Buenos Aires, v.1, n. 1, p. 75-89, jan./.jun. 2016. 